\title{
Environmental Exposure and Nonadherence with Medicines Directly Correlate with Exacerbations and Hospitalization for Asthma: A Population-Based Survey from UAE
}

\author{
Bassam Mahboub, ${ }^{1}$ Mayank Vats, ${ }^{2}$ Shahid Afzal, ${ }^{1}$ Walid Sharif, ${ }^{1}$ \\ and Mohammed Nizam Iqbal ${ }^{1}$ \\ ${ }^{1}$ Department of Pulmonology and Allergy, Rashid Hospital, P.O. Box 4545, Dubai, UAE \\ ${ }^{2}$ Pulmonary Medicine, Al Qasimi Hospital, Sharjah, UAE \\ Correspondence should be addressed to Mayank Vats, drmayankvats@gmail.com \\ Received 30 November 2011; Accepted 15 January 2012
}

Academic Editors: A. Celi, C. Flores, A. Miyazato, and A. M. Sciuto

Copyright () 2012 Bassam Mahboub et al. This is an open access article distributed under the Creative Commons Attribution License, which permits unrestricted use, distribution, and reproduction in any medium, provided the original work is properly cited.

\begin{abstract}
Acute severe exacerbation of asthma is directly related with the uncontrolled asthma including noncompliance with the medicines and exposure to the environmental factors. To our knowledge, none of the community-based study has explored the prevalence of asthma and other factors (namely, pattern of symptoms, environmental/occupational/housing/behavioral pattern/misperception about asthma, and educational factors) contributing to the exacerbation of asthma. We also studied the nonadherence issues related to the management of asthma in the United Arab Emirates (UAE). By using European Community Respiratory Health Survey (ECRHS) questionnaires and pooled data from AIRGNE (UAE) study, we aimed to determine the above-mentioned factors in the general population by means of a cross-sectional assessment of a random sample of 1,229 participants of which $62.97 \%$ were male and $20.01 \%$ were UAE nationals, with a mean age $( \pm S D)$ of $32.9( \pm 14.1)$ years. Prevalence of individual respiratory symptoms from the ECRHS questionnaire in all participants ranged from 8 to $10 \%$, while those participants aged 20-44 years presented a lower prevalence in all symptoms $(P<0.05)$. Conclusion. Certain specific persistent environmental factor along with nonadherence to the controller medicines is a significant factor leading to uncontrolled asthma with consequent exacerbations, morbidity/mortality, and health care cost in UAE.
\end{abstract}

\section{Introduction}

Asthma is a common chronic disease with a very heterogeneous distribution, and its prevalence has increased substantially over the past 5 decades throughout the globe, particularly among children, yet the reasons for this increase remain unknown [1]. The disease represents a significant burden, not only in terms of morbidity/mortality and reduced quality of life of patients, but also in terms of health care costs $[2,3]$.

Recent international surveys of asthma prevalence, particularly those from the European Community Respiratory Health Survey (ECRHS) [4] and the International Study of Asthma and Allergies in Childhood (ISAAC) [5], have led to an increased understanding of the worldwide distribution of asthma. While Western Europe has some of the highest asthma prevalence rates in the world, the ISAAC study not only found that the prevalence is high in English-speaking countries but it also identified new hot spots with higher than expected rates of asthma in participating centers in other countries in Latin America, Asia, and elsewhere [6].

Asthma Insights and Reality (AIR) studies aimed to assess the discrepancy between perceived symptoms and subjective assessments versus objective control and the burden of asthma in order to determine the implementation status of the goals and management recommendations advocated by GINA and were conducted in many countries including Asthma Insights and Reality (AIR) in Europe (AIRE) [7], Asthma in America [8], and Asthma Insights and Reality in Asia-Pacific (AIRAP) [9] and in Latin America (AIRLA) [10].

Data on the distribution of asthma in the Gulf and Near East (GNE) region are scarce. Although studies have been 
carried out, these have involved relatively small samples of patients selected from a limited number of clinical or other institutional settings, and recent data are not available.

The Asthma Insights and Reality in the Gulf and the Near East (AIR GNE) survey was a continuum of AIR studies to assess the quality of asthma treatment and control in five selected countries of the GNE, documenting the experience of a wide cross-section of patients with asthma in the community [11].

The ECRHS was the first study that assessed the prevalence of asthma and allergic disease in 22 countries using an identical and standardized protocol. The three main objectives of the survey were (1) to estimate the variation in the prevalence of asthma, asthma-like symptoms, atopic sensitization, and bronchial lability in Europe; (2) to estimate the variation in exposure to known or suspected risk factors for asthma, to measure their association with asthma, and to assess further the extent to which they explain variations in the prevalence across Europe; (3) to estimate the variation in treatment practice for asthma in the European Community.

The ECRHS II (follow-up study to the ECRHS-I) was planned to assess the incidence and prognosis of allergy, allergic disease, and low lung function in adults; describe the distribution of exposure to associated environmental risk factors; determine the extent to which exposure to these risk factors are attributable to disease; identify subgroups within the population most at risk and to collect and store blood samples suitable for DNA analysis that can be linked to health and environmental data in the future.

It is therefore now an appropriate time to revalidate the results of the ECRHS in UAE perspective covering often forgettable aspects of this brittle disease. Hence, we conducted the similar survey in UAE to compare our findings with the standard ECRHS survey and to find out specific reasons pertaining to geographic/environmental/occupational/social factors for the uncontrolled asthma with consequent high rates of acute severe exacerbations resulting in hospitalization, morbidity, and mortality so that corrective measure could be taken in order to maintain best control of asthma.

\section{Material and Methods}

A large population-based observational prospective study (face to face community survey) was conducted across the UAE with the objective to see the prevalence of asthma and allergic disease and the pattern of disease along with the adherence to the medicine and environmental factors (occupational/housing/air pollution) specific to UAE predisposing to asthma. Other studied parameters included perception of patients about the disease, level of control, use of steroids, education, and awareness of asthma in patients and physicians.

All participants were informed of the voluntary nature of this research and gave informed written consent. The research protocol was approved by Clinical Research Ethics Authority of Dubai. Total of 1,229 individuals were screened across the seven emirates of UAE. Following are the percentage of respondents from each emirates: Abu Dhabi: 34.1\%,
Dubai: 32.2\%, Sharjah: 19.3\%, Ajman: 5\%, Umm al-Quwain: 1.2\%, Ras al-Khaimah: 5.1\%, and Fujairah: $3.1 \%$.

Interviews were conducted around various public locations including town centres, malls, outside mosques, and industrial areas from January to March 2010. The ECRHS II screener questionnaire was translated in Arabic, and participants were interviewed in a side-by-side bilingual version so that respondents had the option to answer questions in the language they understand. Any discrepancies/inconsistencies were solved by the consensus. All interviews were administered by an interviewer. The interviewers were trained before starting the survey, the questionnaire and instructions were studied, and any difficulties were discussed and resolved. Special attention was given to the flow of questions in order to get the best answer from the survey population. As per standard quality control procedures, all materials were piloted. There was also a personal briefing of all interviewers in each region, and each interviewer conducted two pilot interviews and reviewed the completed questionnaires with a supervisor before starting fieldwork. Completed questionnaires were checked locally and again centrally. One interviewer took the questionnaire from 10 or more subjects and was always witnessed by an experienced person who can identify mistakes or doubtful points that need clarification.

Respondents who answered positively (Yes) to 1 of 4 designated questions (question 1 or 4 ; or 5 ; or 7 ) in the screener questionnaire were invited to answer a modified version of the ECRHS II main questionnaire (bilingual in English and Arabic) (see Figure 1).

Special emphasis was given over the environmental factors specific to UAE including local/regional nuances that were applicable like the shisha (water pipe) smoking, air conditioner/refrigerators types used/indoor and outdoor pollution, and the use of trade/brand names for antiasthmatic drugs, and so forth. The Main Questionnaire was administered on the spot after the screener, or follow-up appointments were arranged between the interviewer and respondent to complete the 86-question-long Main Questionnaire.

\section{Results}

Out of 1229 respondents who completed the Screener Questionnaire, demographic distribution was males $(n=774)$; females $(n=455)$ in age groups of $0-19$ years $(n=252) ; 20$ 59 years $(n=939) ;>60$ years $(n=29)$, and 9 respondents refused to disclose their age (Figure 1).

Key Findings from the Screener Questionnaire $(n=1229)$ (Table 1). 125 of the 1229 (10.1\%) respondents had wheezing or whistling in their chests at any time in the last 12 months.

Main Questionnaire. Qualification criteria for main questionnaire: Answer "Yes" to

Q1: Have you had wheezing or whistling in your chest at any time in the last 12 months? $(66.5 \%, n=125 /$ 188); or 


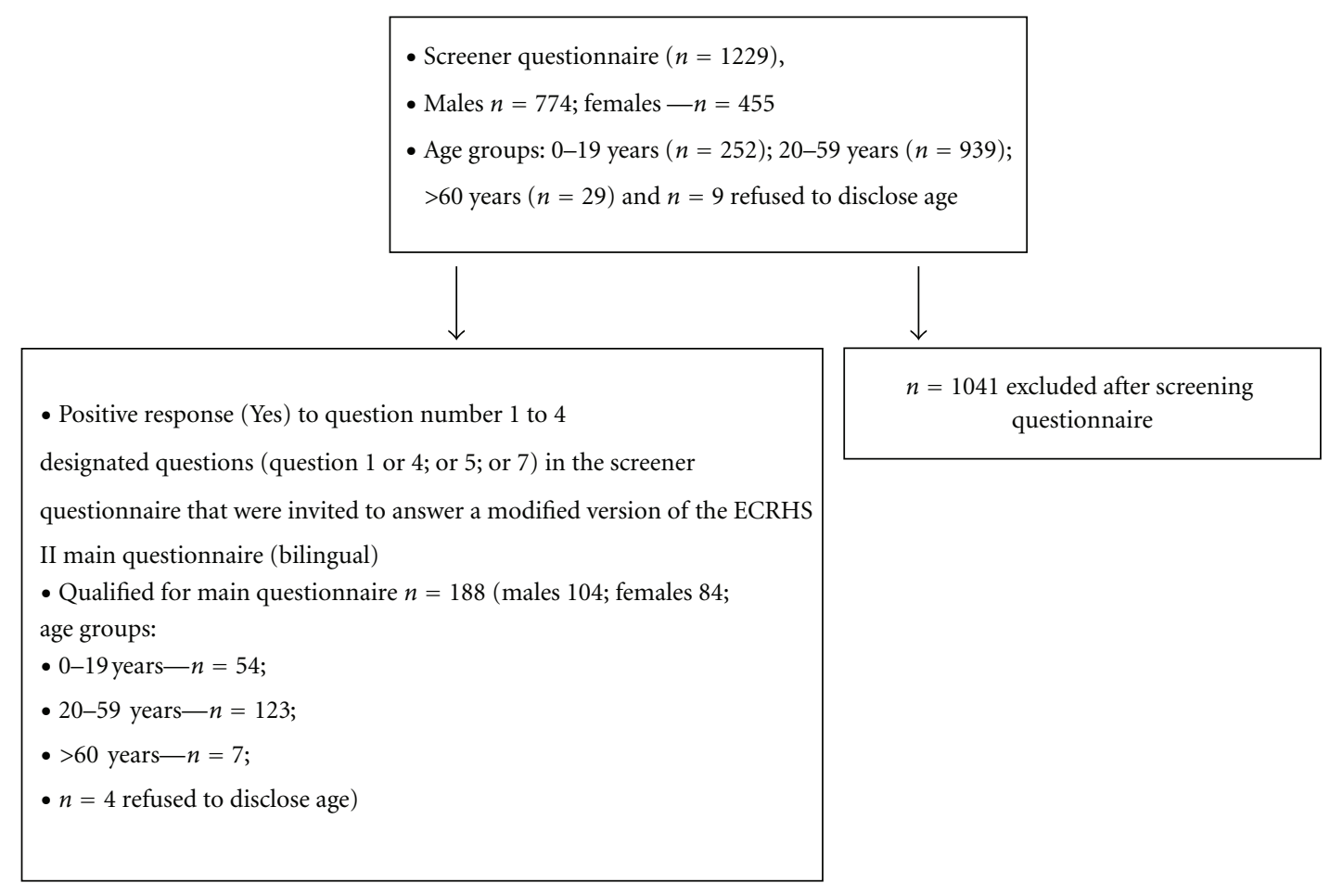

FIgURE 1: Flow Diagram of the selection/case questionnaire.

TABLE 1: Symptoms according to the ECRHS screening questionnaire in participants by age group.

\begin{tabular}{|c|c|c|c|c|}
\hline $\begin{array}{l}\text { ECRHS screening questionnaire symptoms } \\
\text { within the last } 12 \text { months, } n(\%)\end{array}$ & $\begin{array}{c}\leq 19 \mathrm{yr} \\
n=237(19.4 \%)\end{array}$ & $\begin{array}{c}20 \text { to } 44 \mathrm{yr} \\
n=702(57.5 \%)\end{array}$ & $\begin{array}{c}\geq 45 \mathrm{yr} \\
n=281(23.0 \%)\end{array}$ & $\begin{array}{c}\text { All } \\
n=1220^{*}\end{array}$ \\
\hline Wheezing/whistling & $31(13.1 \%)$ & $57(8.1 \%)$ & $34(12.1 \%)$ & $122(10.0 \%)$ \\
\hline Wheezing with breathlessness & $27(11.4 \%)$ & $50(7.1 \%)$ & $32(11.4 \%)$ & $109(8.9 \%)$ \\
\hline Wheezing without a cold & $24(10.1 \%)$ & $43(6.1 \%)$ & $31(11.03 \%)$ & $98(8.0 \%)$ \\
\hline Woken up with chest tightness & $32(13.5 \%)$ & $53(7.5 \%)$ & $34(12.1 \%)$ & $119(9.8 \%)$ \\
\hline Woken up by shortness of breath & $30(12.7 \%)$ & $51(7.3 \%)$ & $30(10.7 \%)$ & $111(9.1 \%)$ \\
\hline Woken up by an attack of coughing & $30(14.8 \%)$ & $59(8.4 \%)$ & $33(11.7 \%)$ & $127(10.4 \%)$ \\
\hline Attack of asthma & $28(11.8 \%)$ & $42(6.0 \%)$ & $27(9.6 \%)$ & $97(8.0 \%)$ \\
\hline Currently taking asthma medications & $22(9.3 \%)$ & $46(6.6 \%)$ & $29(10.3 \%)$ & $97(8.0 \%)$ \\
\hline Nasal allergies (including hay fever) & $22(9.3 \%)$ & $46(6.6 \%)$ & $15(5.3 \%)$ & $83(6.8 \%)$ \\
\hline
\end{tabular}

${ }^{*} n=9$ refused to disclose their age.

Q4: Have you been woken by an attack of coughing at any time in the last 12 months? $(66.5 \%, n=125 / 188)$; or

Q5: Have you had an attack of asthma in the last 12 months? $(51.6 \%, n=97 / 188)$; or

Q7: Do you have any nasal allergies including hay fever? $(36.2 \%, n=68 / 188)$.

Total number of respondents who qualified for main questionnaire was 188 (males $n=104$; females $n=84$ ) in age group of $0-19$ years $(n=54) ; 20-59$ years $(n=123) ;>60$ years $(n=7)$. Four respondents refused to disclose their age.

Following Are the Findings of the Main Questionnaire ( $n=$ 188). Key Findings on Known Asthmatics: $58.5 \%$ respondents claimed to have ever had asthma and average age when they first experienced an asthma attack was 13.5 years. These attacks were most frequently experienced in January/February (26.1\%) and November/December (19.1\%). Out of these 188 respondents, only $47.9 \%$ were currently on medicines for asthma and only $6.9 \%$ had a peak expiratory flow rate (PEFR) meter of their own. 5.3\% asthmatics had been hospitalised before the age of two years for lung disease: $10.1 \%$ had eczema or skin allergy including an itchy rash that was coming and going for at least 6 months. $6.4 \%$ of asthmatics were allergic to analgesics (Ibupofen and aspirin).

Key Findings on Environmental Exposure and Smoking: on questioning about the kind of air cooling device used, the percentages of respondents using fans, central air 
conditioning, and window air conditioning were 59.6\%, $53.7 \%$, and, $51.1 \%$, respectively. A significant number of respondents were having a construction/industrial site near their residence (36.7\%) and place of work (18.6\%). 10.6\% of respondents have smoked for as long as year, and those who have smoked as of one month ago were $8 \%$.

$2.1 \%$ of asthmatics smoked shisha (water pipe smoking) (average no. of shisha smoked was 4 times/week), and 18.1\% were regularly exposed to tobacco smoke in the last 12 months with average of 3.5 hours/day; they were exposed to other people's tobacco smoke:

Key Findings on cooking and housing Conditions of the Patients: predominant source of cooking was gas (main line source, $47.9 \%$ ) followed by bottled gas stove $(39.4 \%)$ and electric stoves $(7.4 \%)$ and microwaves in $3.7 \%$ of patients. 59 $(31.38 \%)$ patients said that they had a door or window to the outside air open most of the time when cooking over the last four weeks, and majority have a cooker with an extractor fan. Around $92 \%$ patients have rugs and fitted carpets covering their whole bedroom floors, and (47.3\%) have a carpet/rug between 1 and 5 years old in the room which they use most during the day.

Fourteen patients $(7.4 \%)$ claimed that they have been mould or mildew (other than food) inside their homes especially bathrooms, kitchen, and living areas. When the patients were asked about that whether they have taken any measures to reduce allergen or exposure to allergen in their home, the reply was that $8.6 \%$ bought new carpet and $17.6 \%$ used antidust mite sprays.

Questioning about having pets revealed that $5.3 \%$ currently keep cats, $1.1 \%$ have dog, and $4.8 \%$ currently keep birds at home. The most common reaction experienced by patients in close proximity to animal or to dusty parts of the house, pillows or duvets and trees, grass or flowers is runny/stuffy nose or sneezing (20.7-45.7\%) and getting itchy/watering eyes in response to the dust (16\%) and (14.4$33.5 \%)$ feeling a shortness of breath.

Key Findings on Treatment and Follow-up Visits by Asthmatics: $40.4 \%$ ( $n=76$ ) were using inhaled short acting beta-2-agonist as a choice of medication (rescue therapy) in the last 12 months. Long-acting beta-2-agnonist was used by only $6.9 \%$ of patients. $35.1 \%(n=66)$ asthmatics were using ventolin (salbutamol) as the most commonly used inhaled medicine (average dose per puff used: $125 \mu \mathrm{gm}$ ), and the most commonly used oral medicine was ventolin CR (salbutamol) in $4.3 \%$ patients. 44 patients $(23.4 \%$ ) claimed to have used some medication to treat a nasal disorder using nasal sprays for an average of 7.5 years. Sixteen patients $(8.5 \%)$ were using antihistamine pills for nasal disorders (average of 10.1 years).

$20.7 \%$ patients claimed that they take all the medicine prescribed for their breathing, but only when their breathing gets worse. $29.8 \%$ of patients have been given regular appointments by a doctor (or nurse), and only $9.6 \%$ were advised for a clinical or laboratory test to diagnose asthma/ wheezing or shortness of breath in the last 12 months. 19.7\% have used other forms of remedies to help them breathe, namely, breathing exercises $9 \%$, diet control $6.9 \%$, swimming and other exercises $4.3 \%$, and homeopathy $3.7 \%$. As far as the occupation is concerned of the studied population, 30.9\% were employed, $23.9 \%$ were full-time students, and $19.1 \%$ were full-time house persons.

\section{Discussion}

This is the first population-based study using ECRHS questionnaires to assess the prevalence of asthma in the UAE and to determine the factors (e.g., environmental/occupational/ housing/perception and control of disease by patients and physicians) contributing to the exacerbation of asthma with resultant morbidity and mortality. Prevalence of asthma in adults and children is expected to be high in UAE although the exact data are not available for the same. ISAAC asthma centre in UAE reported a prevalence of physician-diagnosed asthma of $13 \%$ [13]. In current survey, $10.1 \%$ of asthma patients had allergic disorders (eczema/skin allergy/itchy rash) which is an important risk factor for the development of asthma.

We found that the environmental/occupational/housing factors responsible for allergy and asthma are highly prevalent in UAE. Central AC/window AC were the primary source of cooling in the majority of houses; however, patients were not very sure of the cleanliness of the AC ducts. About 7\% patients had visible moulds in their house. More than half of patients were living close to the construction sites/industry site with heavy exposure to the fine dust and air pollution. One peculiar environmental factor in UAE is that many sensitizing aeroallergens from the desert can worsen asthma leading to unscheduled ER visits and hospitalization [14, 15]. Sudden heavy exposure to dust and sand storm may precipitate acute severe asthma in uncontrolled asthmatics [16].

Low parental education, low birth weight/prematurity, family history of asthma, smoking, and the exposure to indoor/outdoor allergens such as house dust mites and pollen are all known contributing factors in this region $[17,18]$.

A high number of patients in this survey were smoker including the shisha (water-pipe smoking) and passive smoking contributing to exacerbation of asthma. Average annoyance rating from outdoor air pollution (including traffic) was $6.1 \%$ in their current house versus $6.4 \%$ in previous house on a visual analogue scale of 0 to 10 . These figures directly reflect high level of air pollution in the UAE and that patients changed their house due to high level of annoyance from the outdoor air pollution.

There is, undoubtedly, a genetic component to asthma, and it seems possible that changing patterns of environmental influences, such as exposure to microorganisms, pollutants, indoor and outdoor allergens, and diet, exert a strong influence on the development of the disease in susceptible individuals [19].

In present survey, a large number of asthma patients were having pets and carpets in their house exposing them to persistent source of pet's allergen, dust, and dust mites with very high potential of allergic exacerbation of asthma. Considering the above findings, we strongly recommend that patients should always be educated about the environmental control to prevent exacerbation of asthma. In one urban-suburban 
comparative study, Wieringa et al. found that house dust mite allergy is a major determinant of occurrence of prior (childhood) asthma in urban regions [20]; we speculate that this also holds very true in UAE.

One of the most frustrating findings was overreliance on the rescue medicines our $39.4 \%$ of asthmatics were on ventolin inhaler or tablets. Most of the patients were not aware about the names of other inhalers and were unsure about the use of inhaled corticosteroids (ICS). Use of PEFR or clinical or laboratory test for the diagnosis and control of asthma was very low. Only $29.8 \%$ of patients have been given regular follow-up appointments. AIRGNE study, also revealed the same findings. In AIRGNE study the use of preventive treatment of asthma, that is, ICS was very low (5.5\% in UAE and $6.0 \%$ in Oman). The ratio of ICS to shortacting bronchodilators was well below the recommended ratio of $>1$ in all five countries [11].

Another important finding of our survey was that a significant percentage (19.7\%) of patients was using alternate remedies to help them breath including but not limited to breathing exercises, diet control, swimming, exercises, and homeopathy despite having ample knowledge about the nature and the treatment options for the asthma and education delivered by the physicians.

Although we did not per se collected data on the adherence on the maintenance treatment of asthma because it was not a part of the standard ECRHS II questionnaire, the AIRGNE study UAE data could be extrapolated in order to see the compliance/adherence on the controller medicine and this has been found to be very low in AIRGNE study. The main goal of the discussion is to emphasize the relationship of noncompliance and nonadherence to treatment with the exacerbation of acute severe asthma; hence, we pooled the data from our UAE data base from AIRGNE and ECRHS survey.

The term compliance is defined as the extent to which a patient's behavior matches the prescriber's advice, but, recently, it has mostly been superseded by the term adherence, a similar concept but having fewer negative connotations from physician/patient relationship point of view [21]. Adherence is defined as the extent to which the patient's behavior matches agreed recommendations from the prescriber.

It is a well-known fact that adherence to the recommended treatment is the cornerstone of the control of the chronic medical conditions like asthma, hypertension, diabetes, and so forth. However, it is frustrating to know for the clinician that more than half of the patients are not adhering to the treatment as prescribed. Asthma is a cause of concern due to under diagnosis, under investigated, under control and nonadherence to treatment [22-24]. A recent report from WHO suggests that $50 \%$ of patients from developed world with chronic diseases do not take their medications as recommended $[25,26]$. In developing countries, the situation may be even more worse when considering together all the issues related with poor access to health care, lack of appropriate diagnosis, and limited access to medicines. Poor adherence seriously threatens any effort to tackle chronic illness [25].
In asthma, adherence rates are particularly problematic, generally ranging from 30 to $70 \%$ [27] with $<50 \%$ of children adhering to their prescribed inhaled medication regimens [28]. This is greatly concerning, given the vulnerability of these patients to progressive, irreversible airways obstruction, and risk of frequent emergency room (ER) visits and hospitalization for the exacerbation of asthma.

In a retrospective study determining the medication compliance and disease exacerbation in patients with asthma, Stern et al. reported that, based on the median medication possession ratio (MPR), more-compliant patients were less likely to experience exacerbation than less-compliant patients (odds ratio, 0.94; 95\% confidence interval, 0.91$0.97 ; P<0.001)$. They also concluded that, as the criteria for compliance became more stringent, more-compliant patients became increasingly less likely to have exacerbation versus less-compliant patients [29].

Another study by Camargo et al. demonstrating association between common asthma therapies and recurrent asthma exacerbations in children found that patients who had a claim for budesonide inhalation suspension had a lower risk of a subsequent hospitalization or ER visit (HR-0.55; 95\% CI, 0.41-0.76; $P<0.001$ ) than patients who did not have budesonide inhalation suspension claims. Other controller medications were not associated with a reduction in the risk of subsequent asthma exacerbations. Adherence to medication was poor (a median MPR of 0.08 for budesonide inhalation suspension and a median MPR of 0.16 for any asthma controller medication). The odds of a repeat hospitalization or ER visit were significantly lower for children who were adherent to their controller medication [30].

Another study by Milgrom et al. for evaluation of the adherence of asthmatic children to regimens of ICS and betaagonists revealed that the median use of ICS reported by patients on their diaries was $95.4 \%$, whereas the median actual use of ICS was $58.4 \%$. More than $90 \%$ of patients exaggerated their use of ICS, and diary entries of even the least compliant subjects reflected a high level of adherence. The median compliance with ICS was $13.7 \%$ for those who experienced exacerbations and $68.2 \%$ for those who did not. They strongly recommend electronic monitoring over patients diary monitoring to see the actual compliance with asthma medicines [28].

ECRHS survey revealed that the compliance of those patients who had received a medical prescription was found to be low in all countries (median 67\%) but with wide variations (ranging from $40 \%$ in USA to $78 \%$ in Iceland). USA, Australia, and Sweden had significantly lower rates. During exacerbations, compliance rates increased to $72 \%$, in USA, it improved to $66 \%$ but, in Australia and Sweden, remained significantly lower than the median [31].

In USA and Brazil, visits to the ER have been used as a substitute for regular medical appointments, which is totally inappropriate and leads to failures in the treatment and control of the disease $[32,33]$. This places a considerable onus on the children with asthma (days missed from school) and on their parents (days missed from work), as well as on the health care system (high costs). This is found to be true in UAE. Frequent ER visits and hospitalizations contribute 
TABLE 2: Evaluation of asthma burden in the past year in UAE by comparison to AIRGNE results.

\begin{tabular}{lcc}
\hline & UAE & AIRGNE total \\
\hline Asthma burden in the past year & 52.8 & 51.7 \\
School absence in children, \% & 16 & 29.7 \\
Mean (SD) & $5.3(4.5)$ & $7.9(9.6)$ \\
Work absence in adults, \% & 17.1 & 29.7 \\
$\quad$ Mean (SD) & $3.8(2.7)$ & $7.3(8.1)$ \\
\hline Use of health services in the past year & 4 & 22.5 \\
Hospitalization, \% & 28 & 51.5 \\
Emergency room visit, \% & & 14.6 \\
\hline Current use of medication (past 4 & 5.5 \\
weeks) & 57.5 \\
Use of ICS, \% & 0.12 & 0.26 \\
Use of quick relief treatment, \% & & \\
Ratio ICS/SABA & & \\
\hline
\end{tabular}

ICS: inhaled corticosteroids; SD: standard deviation; SABA: short-acting beta2 agonists.

* (Reprinted with permission from AIR UAE survey [12]).

to tremendous health care cost for asthma (Cost Of ASThma in GNE: COAST-GNE study (personal communication, Dr Bassam M, manuscript under preparation). Patients tend to take $P R N$ treatment for asthma going to ER for symptomatic relief rather than regularly following specialists for the control of asthma. In a current survey, it was observed that $66 \%$ of asthma sufferers mainly treated by general practitioners (GP) and majority of patients (94\%) go back to the same source for asthma care. Under one quarter (22\%), see a different specialist in addition to GP. The frequency of followup visits (including specialist) is "only if problems develop" or 1-2 times/year. This is surprising that only $17 \%$ have scheduled follow-up visits, rest of patients had only unscheduled visits to clinics/ER. This clearly shows significant lack either on the part of health care system including physician or patients themselves with the attitude of "caring of asthma when it worsens," but this needs to be improved in order to improve asthma control and its consequences.

Despite extensive evidence of the effectiveness of the controller medicines in asthma, nonadherence is the major reason for uncontrolled asthma, frequent ER visits, hospitalization, morbidity, mortality, and significant cost throughout the globe as evidenced by other international AIR surveys also. Bender et al. concluded that there is no evidence of recent improvement in the rates of nonadherence, and patients continue on average to take about $50 \%$ of prescribed medication. They recommended that nonadherence could only be assessed in most accurate way when it can be measured objectively rather than relying on patient's or physician's estimate [27].

AIRE survey assessed the current levels of asthma control by patient's perception about control of asthma. Daytime symptoms and asthma-related sleep disturbances at least once a week were reported by $46 \%$ and $30 \%$ patients, respectively. In the past 12 months, $25 \%$ of patients reported an unscheduled ER visit, $10 \%$ reported one or more ER visits, and $7 \%$ reported overnight hospitalization due to asthma. In the past 4 weeks, more patients had used prescription quickrelief medication $(63 \%)$ than ICS (23\%). Patient perception of asthma control did not match their symptom severity and far below their actual asthma control; approximately 50\% of patients reporting severe persistent symptoms considered their asthma to be completely or well controlled.

From our pooled data, we also had similar findings in AIRGNE study that reduction in the ACT score was associated with more hospitalizations and more ER visits in all participating countries ( $\chi^{2}$ for trend $<0.05$ ). The highest use of health services due to exacerbation of asthma was seen in Kuwait, where $27.4 \%$ had been hospitalized and $89.1 \%$ had visited the ER in the last 12 months, while, in UAE, it was 4\% and 28\%, respectively (Table 2) [11]. Mean times hospitalised for exacerbation of asthma (breathlessness/chest tightness/wheeze/cough) were 2.13 times, and mean nights hospitalised were 1.5 nights in the past year. Unscheduled ER visits for exacerbation was $60 \%$ in poorly controlled patients while it was $21 \%$ in the well-controlled group (based on ACT score), directly correlating the ER visits to the poor control of asthma with substantial morbidity (Figure 2). Two thirds (64\%) had suffered sudden severe episodes of asthma during the past year. About $40 \%$ had such attacks at least twice a year, and $11 \%$ of children and $3 \%$ of adults had to be hospitalized for asthma.

Pooled data from AIRGNE (UAE) and ECRHS (UAE) study revealed that use of ICS was $5.5 \%$ and use of quick relief treatment was $47.5 \%$ with a ratio of ICS/SABA $0.12 \%$ (recommended ratio $>1$ ) clearly reflecting the very poor compliance in our patients suggesting an urgent need for continuous efforts to improve the awareness and education for asthma patients at all level of health care system (Table 2).

While enquiring about the compliance with the controller medicines, over two-third of patients (69\%) were not familiar with the effects and benefits of the ICS. Of those patients, who were familiar had varying opinions about the ICS ranging from good to bad effects. Positive opinion 


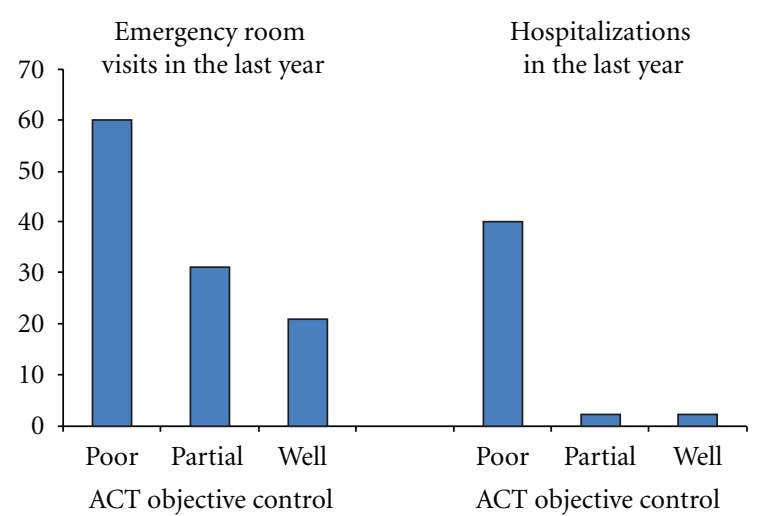

FIgURe 2: Percentage of ER visits and hospitalizations in the last 12 months according to the ACT score. * (Reprinted with permission from AIR UAE survey [12]).

about ICS were fast action (48\%), good control/relief (33\%), expands airways/helps breathing (21\%), long-term efficacy (5\%), while, on the other hand, majority had negative opinion for the ICS including side effects (46\%), causes obesity/swelling (17\%), adversely affects heart (5\%) and lungs (5\%), strong medicine/powerful (3\%); however, 28\% of patients said that there is no disadvantages. Half of patients were unsure or never heard about inflammation of the airways as the underlying cause of asthma reflecting poor level of education delivered by the treating physicians.

Enquiring about problems encountered with medication revealed diverse opinions including treatment does not cure or only a temporary solution $(14 \%)$, less or not effective $(6 \%)$, side effects of medicines (4\%), no fast acting medicines $(4 \%)$, not effective in long term management (2\%), no good doctors or efficient hospitals available for asthma (2\%). Other problems included: sleep disturbances, strong medication, weakness in body, cannot use in public, and not easy for children to use, too much medicine, not completely satisfied. These findings clearly reflect that there is a huge gap of communication between the patients and the physician about the awareness and perception of the disease and its control. This also signifies an immense need for the implementation of the standard national/international guidelines by the health authority in our country.

We speculated about the possible determinants of poor compliance considering social, economic, and geographical barriers. A significant negative correlation was found between patient compliance and rate of hospital/ER visits. It was observed that subjects suffering from more severe asthma did not show better compliance to antiasthmatic treatment than those with milder asthma. Although the data do not allow the confirmation of a cause-effect relationship, it is reasonable to suppose that poor adherence to treatment may result in increased disease severity with consequent hospital/ ER visits. This could have been avoided if the management of the disease had been correct.

Exercise limitation is also a prominent finding in our study; $62.2 \%$ patients claimed that they never exercised reflecting sedentary life style and westernization of society.
This exercise limitation is also contributed by uncontrolled asthma and poor perception of the disease. AIRGNE study had similar findings about the perception of control of asthma by the patients; however, when patients were questioned based on the Asthma Control Test (ACT), there was significant mismatch between the patients perception of controlled asthma versus real control of asthma (Table 3 ). We strongly think that these differences in subjective versus objective control of asthma in AIRGNE study ${ }^{11}$ could be extrapolated in same way in current survey and emphasis should be given to awareness and education about the benefits of well-controlled asthma to all patients.

Although there is considerable confounding factors between country and language and the effects of language and culture on the reporting of symptoms are a relatively poorly explored area, we did not find this as a significant confounding factor because our questionnaire was bilingual (Arabic and English which are the commonest language in UAE).

Various factors, such as income, level of education, and education about the disease, are implicated in the genesis of asthma-related hospitalization since these factors directly influence the access to health care facilities. Similarly, the prevention of predisposing environmental factors is indicated, although the implementation of the consensuses, by emphasizing aspects directly related to the preventive therapy, seems to exert a considerable influence.

World Health Survey by WHO used a standardized survey instrument to compile comprehensive baseline information on health and healthcare expenditure by analyzing the global patterns of self-reported wheeze and doctor-diagnosed asthma, two commonly reported measures of respiratory health [34]. The survey showed that highly industrialized (higher income) countries, such as Australia and countries in Western Europe, had the higher prevalence of current wheezing symptoms and diagnosed asthma, while lower prevalence was found in middle-income countries, particularly in eastern and central Europe. UAE is a high-income group country with high prevalence of current wheezing symptoms and diagnosed asthma resulting from many other influential factors at play, such as increased environmental pollution and westernization of life style in last 20 years, which has been identified as a risk factor for respiratory illness in both children and adults; access to healthcare and disease information (which allow for disease identification, treatment, and management); the highly contested hygiene hypothesis [35-38] which postulates that a lack of exposure to dirt in childhood may increase an individual's susceptibly to respiratory illnesses, asthma in particular, and may explain the high asthma prevalence observed in UAE [39].

One might also expect that the correlation between current wheezing symptoms and asthma diagnosis would vary by socioeconomic and cultural differences, for which national income may be a partial proxy. Country-level features, such as access to healthcare, health literacy, willingness to report symptoms, and cultural differences in how breathing problems are labeled and understood, could all affect the ratio of current symptoms to diagnosis of asthma. In UAE, it has been observed that many physicians especially GP and internists avoid using the term asthma and prefer using the 
TABLE 3: Comparison between objective and subjective evaluation of asthma control.

\begin{tabular}{|c|c|c|c|}
\hline Level of asthma control & $\begin{array}{c}\text { Subjective asthma control } \\
n(\%)\end{array}$ & $\begin{array}{c}\text { Objective asthma control }{ }^{*} \\
n(\%)\end{array}$ & $P$ \\
\hline Poorly and not well controlled & $8(4 \%)$ & $60(30 \%)$ & $<0.05$ \\
\hline Well/completely controlled & $192(96 \%)$ & $140(70 \%)$ & $<0.05$ \\
\hline
\end{tabular}

* Objective evaluation of asthma control according to the Asthma Control Test (ACT).

ACT: 5 to 19-poorly or not well controlled asthma, 20 to 25-well controlled asthma.

* (Reprinted with permission from AIR UAE survey [12]).

term allergy (of respiratory tract), with an intention to make it milder and more acceptable to patients or to their parents; this could have led to underestimation of the number of asthma patients out of total sample size because they might not be told by their doctors that they have asthma [40].

Various international studies have demonstrated that the use of appropriate prophylactic treatment, based on patient education, combined with the prescription of preventive medications, presents a quite favorable cost-effectiveness ratio, resulting in clinical improvement and reduction in the hospitalizations and ER visits [41]. In many well-controlled study conducted among the children, it has been observed that undercontrolled asthma is directly related with the mortality. However, we could not assess this relationship in our patients because it was a community-based survey but, in our patient data-base, inadequate use of controller medicines led to unacceptable high rates of frequent hospitalization for the exacerbation of asthma in last 1 year.

\section{Conclusion}

Present survey clearly shows the pattern of asthma including high prevalence of predisposing factors, namely, environmental/construction work/industrial pollution/occupational/housing/patient's behavioral issues/misperception of disease/lack of educational delivery by the physicians. This implies an immediate need to improve education/communication and awareness among patients and physicians, specifically to reinforce the use of anti-inflammatory medications.

Underestimation of the severity of asthma and overestimation of asthma control by both patients and physicians are important factors contributing to poor asthma control. We strongly recommend treat to the target approach while dealing with asthma patients similar to other chronic conditions to have best control of asthma.

Suboptimal adherence with controller medication is very common with resultant significant morbidity and healthcare costs and should always be considered in all poorly controlled asthma patients. In UAE, the most important issue needs to be dealt with are various ethnic background/cultural belief/behavioral issues/limited access to health care/availability and claims of efficacy of alternative medicines/complexity of the regimen/patient's concerns and prejudices about the efficacy and side effects/steroid phobia/socially disadvantaged groups and cost of the medicines. We strongly recommend that the treatment plans should be developed collaboratively considering all the above-described factors, a strategy to motivate patients to maintain adherence, and a tool to evaluate adherence in subjects with poor disease control. Improved adherence will definitely lead to improved asthma control. Hence, we suggest that health care systems should encourage and support the allocation of sufficient resources in a meaningful way to combat the barriers to selfmanagement and other solutions should also be sought. Caregiver-patient relationship should be strengthened and special programs for difficult-to-manage patients must be implemented to improve the outcome of asthma in UAE.

Limitations of the Study. Certain limitations are worth exploring. The sample size of 1229 with 188 patients of asthma may not be representative of all the populations in the UAE and considering the realistic facts with large number of expatriates and immigrant population and the absence of appropriate census. Therefore, more studies recruiting large number of population including representative samples of all ethnic origin are needed to reconfirm our findings. Present survey was conducted in public locations, rather than a doorto-door or random-digit dialing, or other sampling procedure. We did not perform skin-prick test (SPT), blood tests for the measurement of total and specific IgE, spirometry and methacholine challenge (done in ECRHS) due to the cost and manpower reasons.

\section{References}

[1] E. C. Mantzouranis, "Taking your child's breath away-the extension of asthma's global reach," New England Journal of Medicine, vol. 358, no. 12, pp. 1211-1213, 2008.

[2] National Heart, Lung, and Blood Institute, National Institutes of Health; World Health Organization, Global Initiative for Asthma (GINA), NHLBI, Bethesda, Md, USA; WHO, Geneva, Switzerland, 2009, http://www.ginasthma.org/.

[3] R. Beasley, J. Crane, C. K. W. Lai, and N. Pearce, "Prevalence and etiology of asthma," Journal of Allergy and Clinical Immunology, vol. 105, no. 2, supplement 2, pp. S466-S472, 2000.

[4] P. Burney, "Variations in the prevalence of respiratory symptoms, self-reported asthma attacks, and use of asthma medication in the European Community Respiratory Health Survey (ECRHS)," European Respiratory Journal, vol. 9, no. 4, pp. 687-695, 1996.

[5] The International Study of Asthma and Allergies in Childhood Steering Committee, "Worldwide variations in the prevalence of asthma symptoms: the International Study of Asthma and Allergies in Childhood (ISAAC)," European Respiratory Journal, vol. 12, no. 2, pp. 315-335, 1998.

[6] N. Pearce, J. Sunyer, and S. Cheng, "Comparison of asthma prevalence in the ISAAC and the ECRHS. ISAAC Steering Committee and the European Community Respiratory Health 
Survey. International Study of Asthma and Allergies in Childhood," European Respiratory Journal, vol. 16, no. 3, pp. 420 426, 2000.

[7] K. F. Rabe, P. A. Vermeire, J. B. Soriano, and W. C. Maier, "Clinical management of asthma in 1999: the Asthma Insights and Reality in Europe (AIRE) study," European Respiratory Journal, vol. 16, no. 5, pp. 802-807, 2000.

[8] R. J. Adams, A. Fuhlbrigge, T. Guilbert, P. Lozano, and F. Martinez, "Inadequate use of asthma medication in the United States: results of the Asthma in America national population survey," Journal of Allergy and Clinical Immunology, vol. 110, no. 1, pp. 58-64, 2002.

[9] C. K. W. Lai, T. S. de Guia, Y. Y. Kim et al., "Asthma control in the Asia-Pacific region: the Asthma Insights and Reality in Asia-Pacific Study (AIRAP)," Journal of Allergy and Clinical Immunology, vol. 111, no. 2, pp. 263-268, 2003.

[10] H. Neffen, C. Fritscher, F. C. Schacht et al., "Asthma control in Latin America: the Asthma Insights and Reality in Latin America (AIRLA) survey," Revista Panamericana de Salud Publica, vol. 17, no. 3, pp. 191-197, 2005.

[11] M. Khadadah, B. Mahboub, N. H. Al-Busaidi, N. Sliman, J. B. Soriano, and J. Bahous, "Asthma Insights and Reality in the Gulf and the Near East (AIRGNE)," International Journal of Tuberculosis and Lung Disease, vol. 13, no. 8, pp. 1015-1022, 2009.

[12] B. H. Mahboub, S. Santhakumar, J. B. Soriano, and R. Pawankar, "Asthma insights and reality in the United Arab Emirates," Annals of Thoracic Medicine, vol. 5, no. 4, pp. 217221, 2010.

[13] F. Al-Maskari, A. Bener, A. Al-Kaabi, N. Al-Suwaidi, N. Norman, and J. Brebner, "Asthma and respiratory symptoms among school children in United Arab Emirates," Allergie et Immunologie, vol. 32, no. 4, pp. 159-163, 2000.

[14] G. G. Lestringant, A. Bener, P. M. Frossard et al., "A clinical study of airborne allergens in the United Arab Emirates," Allergie et Immunologie, vol. 31, no. 8, pp. 263-267, 1999.

[15] C. I. Ezeamuzie, S. Al-Ali, M. Khan et al., "IgE-mediated sensitization to mould allergens among patients with allergic respiratory diseases in a desert environment," International Archives of Allergy and Immunology, vol. 121, no. 4, pp. 300-307, 2000.

[16] A. Waness, Y. A. EL-Sameed, B. Mahboub et al., "Respiratory disorders in the Middle East: a review," Respirology, vol. 16, no. 8, pp. 755-766, 2011.

[17] W. Al-Kubaisy, S. H. Ali, and D. Al-Thamiri, "Risk factors for asthma among primary school children in Baghdad, Iraq," Saudi Medical Journal, vol. 26, no. 3, pp. 460-466, 2005.

[18] H. A. Sattar, H. Mobayed, A. A. Al-Mohammed et al., "The pattern of indoor and outdoor respiratory allergens in asthmatic adult patients in a humid and desert newly developed country," European Annals of Allergy and Clinical Immunology, vol. 35, no. 8, pp. 300-305, 2003.

[19] S. S. Braman, "The global burden of asthma," Chest, vol. 130, no. 1, supplement, pp. 4S-12S, 2006.

[20] M. H. Wieringa, J. J. Weyler, F. J. van Bastelaer, V. J. Nelen, M. P. van Sprundel, and P. A. Vermeire, "Higher asthma occurrence in an urban than a suburban area: role of house dust mite skin allergy," European Respiratory Journal, vol. 10, no. 7, pp. 14601466, 1997.

[21] R. B. Haynes, D. L. Sackett, and D. W. Taylor, Compliance in Healthcare, John Hopkins University Press, Baltimore, Md, USA, 1979.

[22] M. L. Barreto, S. S. Cunha, N. Alcântara-Neves et al., "Risk factors and immunological pathways for asthma and other allergic diseases in children: background and methodology of a longitudinal study in a large urban center in Northeastern Brazil (Salvador-SCAALA study)," BMC Pulmonary Medicine, vol. 6, article 15, 2006.

[23] National Institutes of Health, Bethesda: National Institutes of Health/US Department of Health and Human Services; Inc., c1998. National Heart Lung and Blood Institute. Practical Guide for the Diagnosis and Management of Asthma, April 2006, http://www.nhlbi.nih.gov/health/prof/lung/asthma/ practgde.htm.

[24] A. Woolcock, A. R. Rubinfeld, J. P. Seale et al., "Thoracic society of Australia and New Zealand. Asthma management plan, 1989," The Medical Journal of Australia, vol. 151, no. 1112, pp. 650-653, 1989.

[25] World Health Organization, Adherence to Long-Term Therapies: Evidence for Action, World Health Organization, Geneva, Switzerland, 2003.

[26] R. Horne, Concordance and Medicines Management in the Respiratory Arena, Hayward Medical Publications, London, UK, 2003.

[27] B. Bender, H. Milgrom, and C. Rand, "Non-adherence in asthmatic patients: is there a solution to the problem?" Annals of Allergy, Asthma and Immunology, vol. 79, no. 3, pp. 177-185, 1997.

[28] H. Milgrom, B. Bender, L. Ackerson, P. Bowry, B. Smith, and C. Rand, "Noncompliance and treatment failure in children with asthma," Journal of Allergy and Clinical Immunology, vol. 98, no. 6, part 1, pp. 1051-1057, 1996.

[29] L. Stern, J. Berman, W. Lumry et al., "Medication compliance and disease exacerbation in patients with asthma: a retrospective study of managed care data," Annals of Allergy, Asthma and Immunology, vol. 97, no. 3, pp. 402-408, 2006.

[30] C. A. Camargo Jr, S. Ramachandran, K. L. Ryskina, B. E. Lewis, and A. P. Legorreta, "Association between common asthma therapies and recurrent asthma exacerbations in children enrolled in a state Medicaid plan," American Journal of HealthSystem Pharmacy, vol. 64, no. 10, pp. 1054-1061, 2007.

[31] I. Cerveri, F. Locatelli, M. C. Zoia, A. Corsico, S. Accordini, and R. de Marco, "International variations in asthma treatment compliance: the results of the European Community Respiratory Health Survey (ECRHS)," European Respiratory Journal, vol. 14, no. 2, pp. 288-294, 1999.

[32] G. A. Friday Jr, H. Khine, M. S. Lin, and L. A. Caliguiri, "Profile of children requiring emergency treatment for asthma," Annals of Allergy, Asthma and Immunology, vol. 78, no. 2, pp. 221-224, 1997.

[33] M. Chatkin, A. M. B. Menezes, E. Albernaz, C. G. Victora, and F. C. Barros, "Fatores de risco para consultas em pronto-socorro por crianças asmáticas no Sul do Brasil," Revista de Saúde Pública, vol. 34, no. 5, pp. 491-498, 2000.

[34] T. Bedirhan-U stin, S. Chatterji, M. Villanueva et al., WHO Multi country Survey Study on Health and Responsiveness 20002001, World Health Organization, World Health Survey, Geneva, Switzerland, 2001.

[35] L. C. Von Hertzen, "The hygiene hypothesis in the development of atopy and asthma-still a matter of controversy?" Monthly Journal of the Association of Physicians, vol. 91, no. 11, pp. 767-771, 1998.

[36] J. Douwes and N. Pearce, "Commentary: the end of the hygiene hypothesis?" International Journal of Epidemiology, vol. 37, no. 3, pp. 570-572, 2008.

[37] S. T. Weiss, "Eat dirt- the hygiene hypothesis and allergic diseases," The New England Journal of Medicine, vol. 347, no. 12, pp. 930-931, 2002. 
[38] S. T. Weiss, "Asthma in early life: is the hygiene hypothesis correct?" Jornal de Pediatria, vol. 84, no. 6, pp. 475-476, 2008.

[39] G. Sembajwe, M. Cifuentes, S. W. Tak, D. Kriebel, R. Gore, and L. Punnett, "National income, self-reported wheezing and asthma diagnosis from the World Health Survey," European Respiratory Journal, vol. 35, no. 2, pp. 279-286, 2010.

[40] N. Al-Busaidi and J. B. Soriano, "Asthma control in Oman national results within the Asthma Insights and Reality in the Gulf and the Near East (AIRGNE) Study," Sultan Qaboos University Medical Journal, vol. 11, no. 1, pp. 45-51, 2011.

[41] S. Sullivan, A. Elixhauser, A. S. Buist, B. R. Luce, J. Eisenberg, and K. B. Weiss, "National Asthma Education and Prevention Program working group report on the cost effectiveness of asthma care," American Journal of Respiratory and Critical Care Medicine, vol. 154, no. 3, pp. S84-S95, 1996. 


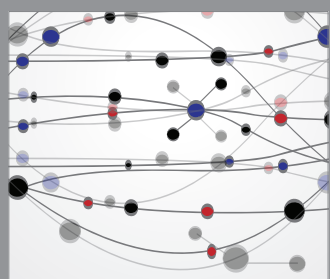

The Scientific World Journal
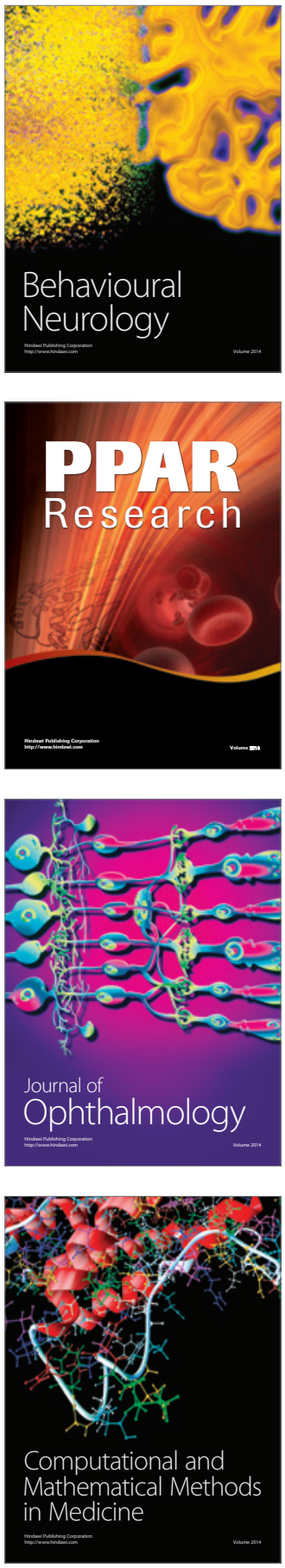

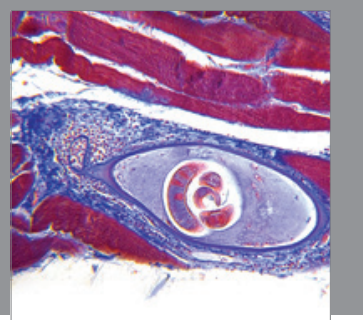

Gastroenterology

Research and Practice
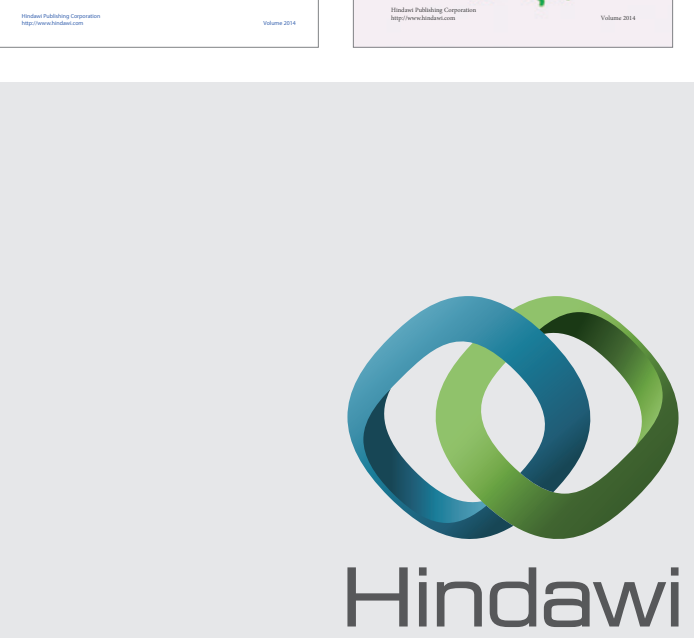

Submit your manuscripts at

http://www.hindawi.com
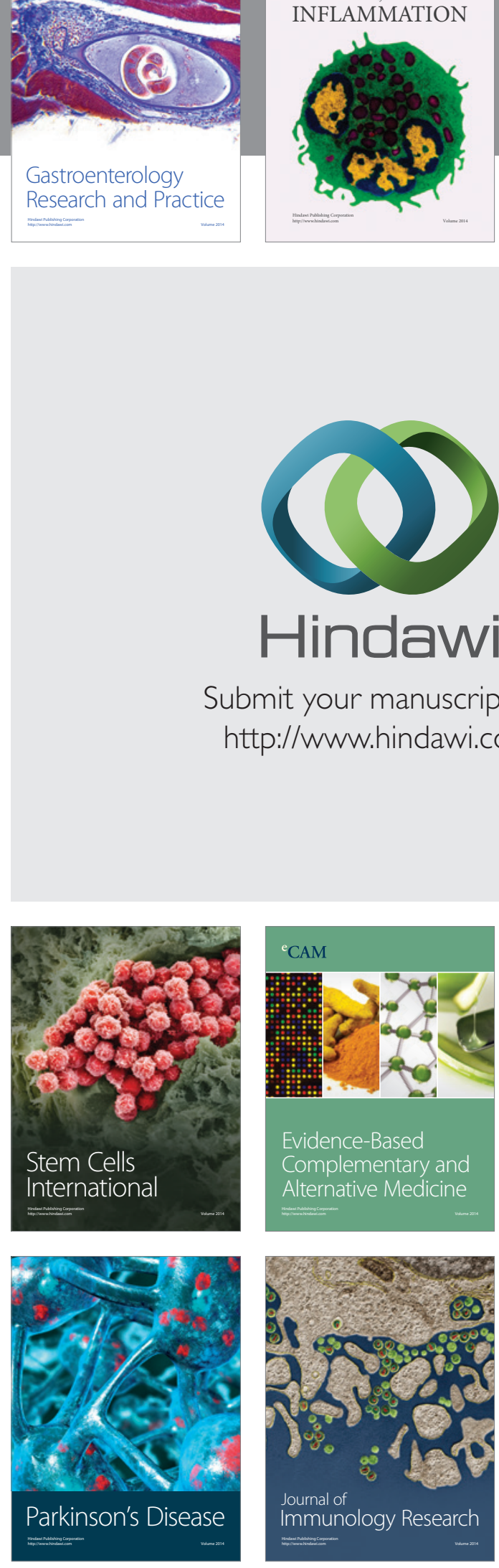

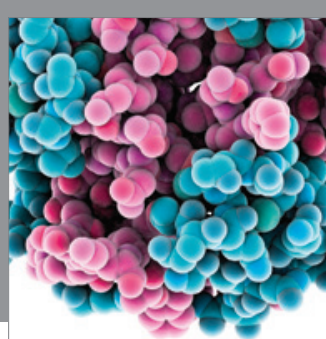

Diabetes Research
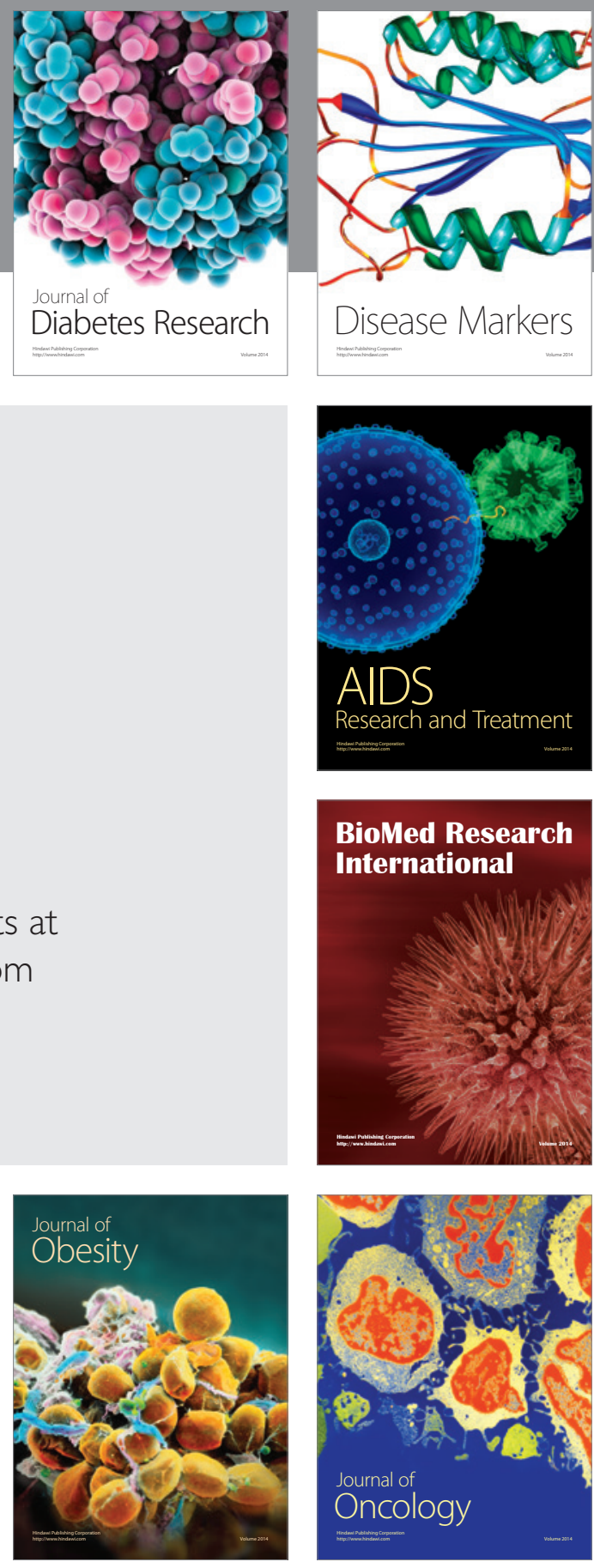

Disease Markers

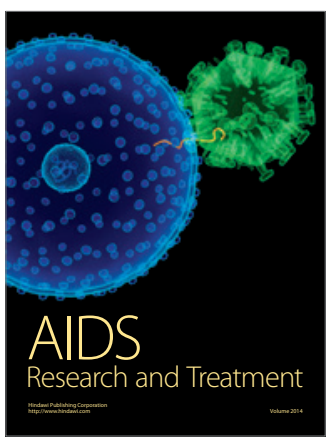

BioMed Research

International
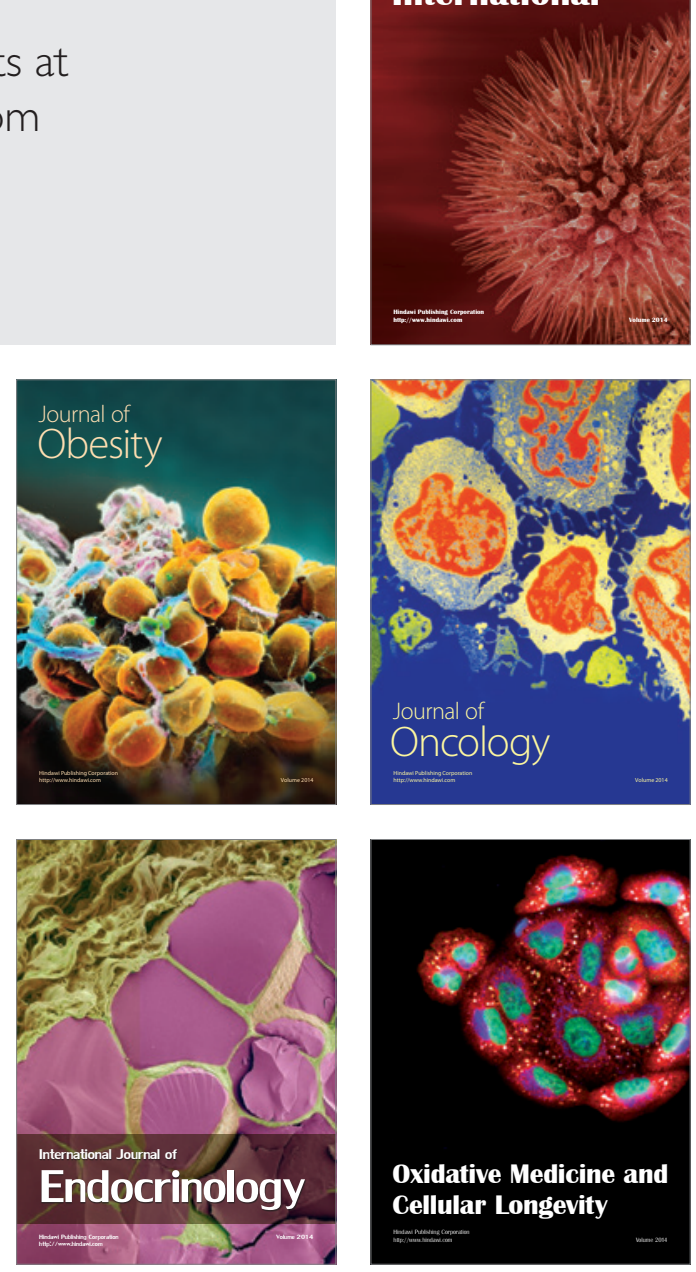